Uluslararası Mühendislik

Cilt/Volume:11 Sayı/Issue:1 Ocak/January 2019

Araştırma Makalesi / Research Article

\title{
Comparison of AHP-TOPSIS and AHP-VIKOR Methods in Product Selection in terms of Inventory Management
}

\author{
Melda Kokoç *1 iD, Süleyman Ersöz ${ }^{2}$ iD \\ ${ }^{1}$ Gazi University, Coordination Office of Eduation, Training and Foreign Relations, 06500, Ankara, TURKEY \\ ${ }^{2}$ Kirlkkale University, Faculty of Engineering, Department, Industrial Engineering, 71450, Kirlkkale, TURKEY
}

\begin{abstract}
Firms must develop and implement effective inventory policies that minimize costs and maximize profits in today's market conditions where extraordinary competition is experienced. Inventory has an important place in the total assets of manufacturing enterprises. Implementation of effective inventory management policies for this important item is crucial for the future of firms. Firms can meet customer needs more effectively by controlling fewer inventories that they classify according to their importance level. In this study, which is prepared by taking advantage of this point of view, application is presented that applies multicriteria decision-making methods to determine the most important product in terms of inventory management. In the process of determining the product in the most important according to criteria determined, AHP method which is frequently used in the literature is applied for calculation weights of criteria. These weights are used in TOPSIS and VIKOR methods and results of these two methods are compared.
\end{abstract}

Key Words

"AHP, Inventory management, Multi-criteria decision making, TOPSIS, VIKOR" 


\section{INTRODUCTION}

Inventory management has great significance as it helps businesses to keep production costs at a low level. In addition, working with minimum inventory provides relief for the financing function of the business. Shift of funding resources, which is generally limited, to other areas has increased competition force of firm. Costs generated by inventories also are increased when they fall below appropriate level, such as they are increased when inventories level goes to above appropriate level. This precise balance can be protected by efficient inventory management. A good inventory management foresees a balanced inventory to meet the needs of firm.

When literature is examined, it is seen that studies are often focused on classification and clustering. For this reason, it was benefited from studies related to classification or clustering which are multi-criteria for inventory management. Zhou and Fan (2007) applied the multi-criteria ABC inventory classification, including some balancing features. Bhattacharya et al. (2007) used the TOPSIS method for $\mathrm{ABC}$ analysis and evaluated the results obtained with ANOVA. Chen et al. (2008) performed multi-criteria ABC analysis by adding "criticality of product" to criteria. Cakir and Canbolat (2008) proposed AHP, which was integrated into fuzzy technique to solve multi-criteria inventory classification problem. Aydın Keskin and Özkan (2013) used the Fuzzy C-Means algorithm, a clustering method for multi-criteria ABC classification. Ertuğrul and Tanrıverdi (2013) applied ABC method and AHP analyzes to stock control of Yarn Company. Özdemir and Özveri (2013) shown differences between the results of classical ABC analysis and AHP in multi-criteria inventory classification. Kılıç et al. (2014), revealed differences between the results of classical ABC analysis and results of BAHP-TOPSIS methods used to classify stocks. Hatefi and Seyed (2015) addressed ABC inventory classification problem with multi-criteria inventory classification approach and proposed a linear optimization method that allows classification of stock items. It is indicated that proposed model significantly reduces processing time when controlling a large number of inventory items and does not require subjective knowledge to operate model. May et al. (2017), tested various inventory prioritization techniques and developed WNO (modified multi-criterion weighted non-linear optimization) method. In this study, it was stated that modified WNO method is consistent and performs more strongly than other possible ranking algorithms. In Kumar et al. (2017)'s study ABC, XYZ, HML and FSN analyzes were implemented to improve the efficiency of balloon manufacturing company's inventory management. For better inventory management, they emphasized that inventories must be periodically classified and updated.

In this study, alternatives chosen by experts from products produced by a company producing agricultural tools were evaluated with multi-criteria decision-making methods by considering certain criteria. AHP-TOPSIS and AHP-VIKOR methods were used to determine the most important product in terms of inventory management and methods results were compared. This study is structured as follows: Section 2 explains AHP, TOPSIS and VIKOR methods. In Section 3, for determining the most important inventory item, stages of approaches applied are explained. In Section 4, conclusions are explained, and results are discussed.

\section{METHODS}

In this section, AHP, TOPSIS and VIKOR, which are multi-criteria decision-making methods, are explained and steps of these methods are presented. In addition, steps of application performed for inventory management, are presented (Table 1).

Table 1. Application Steps

\begin{tabular}{ll}
\hline Steps & Explanation \\
\hline 1 & Definition of problem \\
2 & Examination of literature \\
3 & Determination of criteria \\
4 & Selection of alternatives \\
5 & Creation of hierarchy for decision-making process \\
6 & Obtaining of pairwise comparison matrix for criteria \\
7 & Calculation of criteria weights by using AHP \\
8 & Ensuring of consistency of criteria weights \\
9 & If it is not consistency, regenerate pairwise comparison matrix, else go to Step 9 \\
10 & Determination of alternatives' ranking with TOPSIS \\
11 & Determination of alternatives' ranking with VIKOR \\
\hline
\end{tabular}

\subsection{AHP Method}

AHP (Analytic Hierarchy Process) was introduced by Saaty (1980). It is a powerful and easy-to-understand, multi-criteria decisionmaking method that enables you to combine objective and subjective factors in the decision-making process that are often used to solve complex problems. AHP requires that the decision-making problem be described in as much detail as possible, and the stages referred to as the hierarchy must be examined. A hierarchical model consisting of goals, criteria, sub-criteria and alternatives is used in the AHP technique (Aydın, 2009). This method is based on three basic principles: building hierarchies, determining weights, and ensuring consistency. Steps of the AHP method are described below: 
Step 1: Definition of decision problem: In the first step, the decision-making problem must be clearly defined and determined. The necessary decision criteria and alternatives should be listed to realize the purpose.

Step 2: Creation of hierarchical structure: When hierarchical structure of AHP is considered, decision maker's goal is at the top level. Criteria and sub-criteria are included in hierarchical level as the levels are lowered. As hierarchy level decreases, sub-criteria are reached, and criteria are elaborated, in other words, becoming clearer.

Step 3: Creation of a pairwise comparison matrix: This matrix forms the basic data of AHP. Matrix is based on a comparison of all alternatives under criteria. Comparison matrix, which is obtained by expert opinions and related literature, is based on scaling from 1 to 9. Scales used are generally 1-9 scale developed by Saaty (Saaty, 1980). Experts make evaluations according to this scale and all evaluations are combined to obtain the comparison matrix (Görgülü, 2013). The importance ratings used in scale and their definitions and explanations are given in Table 2.

Table 2. Intensity of importance scale and its description

\begin{tabular}{ll}
\hline Intensity of importance & Definition \\
\hline 1 & Equal importance \\
3 & Moderate importance \\
5 & Strong importance \\
7 & Very strong importance \\
9 & Extreme importance \\
$2,4,6,8$ & Intermediate values \\
\hline
\end{tabular}

Let $C_{i}$ and $a_{i j}$ represent respectively criteria and evaluation of between criteria, pairwise comparison matrix (A) of size $\mathrm{n}^{*} \mathrm{n}$ is formed as shown in Table 3.

Table 3. Pairwise comparison matrix

\begin{tabular}{|l|l|l|l|l|l|}
\hline & & $\mathrm{C}_{1}$ & $\mathrm{C}_{2}$ & $\ldots$ & $\mathrm{C}_{\mathrm{n}}$ \\
\hline \multirow{4}{*}{$\mathrm{A}=$} & $\mathrm{C}_{1}$ & 1 & $\mathrm{a}_{12}$ & $\ldots$ & $\mathrm{a}_{1 \mathrm{n}}$ \\
\cline { 2 - 6 } & $\mathrm{C}_{2}$ & $1 / \mathrm{a}_{12}$ & 1 & $\ldots$ & $\mathrm{a}_{2 \mathrm{n}}$ \\
\cline { 2 - 6 } & $\ldots$ & $\ldots$ & $\ldots$ & $\ldots$ & $\ldots$ \\
\cline { 2 - 6 } & $\mathrm{C}_{\mathrm{n}}$ & $1 / \mathrm{a}_{1 \mathrm{n}}$ & $1 / \mathrm{a}_{2 \mathrm{n}}$ & $\ldots$ & 1 \\
\hline
\end{tabular}

Personal provisions of decision maker are used when making pairwise comparisons of alternatives. In decision-making process, not only numerical solutions are sought, but also personal ideas and considerations are taken into consideration. When pairwise comparisons are made, evaluations are simplified because only two elements are considered. On the other hand, verbal expressions can also be used if evaluations cannot be quantified. Decision maker can evaluate alternatives by taking both objective and subjective factors together.

Step 4: Calculation of the consistency ratio: For AHP results to be valid, matrix A must be a consistent matrix. In a consistent matrix A, $w_{j}$ (weight vector) are calculated under a condition $\sum_{j=1}^{n} w_{j}=1$. Consistency Index (CI) is calculated via Eq. (1). $\lambda_{\text {max }}$ value in equation, is obtained by dividing the weight vector by the respective relative importance values.

$C I=\frac{\lambda_{\max }-n}{n-1}$

Randomness indicator (RI) depends on size of comparison matrix. RI developed for matrices with a dimension between 1 and 15 are shown in Table 4 (Boulos, 2003). After CI and RI values are calculated, consistency ratio (CR) is calculated by Eq. (2). To obtain consistent comparison matrix, CR must less than equal to 0,10 .

$C R=\frac{C I}{R I}$

Table 4. Randomness indicator values

\begin{tabular}{|l|l|l|l|l|l|l|l|l|l|l|l|l|l|l|l|}
\hline $\mathrm{n}$ & 1 & 2 & 3 & 4 & 5 & 6 & 7 & 8 & 9 & 10 & 11 & 12 & 13 & 14 & 15 \\
\hline $\mathrm{RI}$ & 0,00 & 0,00 & 0,58 & 0,90 & 1,12 & 1,24 & 1,32 & 1,41 & 1,45 & 1,49 & 1,51 & 1,48 & 1,56 & 1,57 & 1,59 \\
\hline
\end{tabular}

\subsection{TOPSIS Method}

TOPSIS (Technique for Order Preference by Similarity to Ideal Solution) was developed by Hwang and Yoon (1981) as a multicriteria decision-making technique. The basis of this method is based on choice of positive-ideal solution at the shortest distance and negative-ideal solution at the farthest distance (Opricovic and Tzeng, 2004). This is an appropriate method in terms of decision makers who escape from risks related decision making process. Steps of TOPSIS method are described below: 
Step 1: Creating the decision matrix $\left(\boldsymbol{A}_{i j}\right.$ ): In this step, decision matrices that have alternatives in their rows and have evaluation criteria in their columns, are created. $a_{i j}$ denotes the actual value of the alternative $i$ in the decision matrix according to the criterion j.

$A_{i j}=\left[\begin{array}{cccc}a_{11} & a_{12} & \ldots & a_{1 n} \\ a_{21} & a_{22} & \ldots & a_{2 n} \\ \vdots & \vdots & \ddots & \vdots \\ a_{m 1} & a_{m 2} & \ldots & a_{m n}\end{array}\right]$

Step 2: Generation of normalized decision matrix $\left(N_{i j}\right)$ : After generating decision matrix, normalized decision matrix is obtained by using Eq. (3).

$r_{i j}=\frac{a_{i j}}{\sqrt{\sum_{k=1}^{m} a_{k j}^{2}}}$

Step 3: Generate weighted normalized decision matrix $(V)$ : After determining relative weight values $\left(w_{i j}: \mathrm{i}: 1,2, \ldots, \mathrm{n}\right)$ for evaluation criteria, the elements in each column of $\mathrm{N}$ matrix are multiplied by $w_{i j}$ value to form the $\mathrm{V}$ matrix. The weighted normalized decision matrix is obtained by Eq. (4).

$V_{i j}=w_{i j} \times N_{i j}$

Step 4: Creation of ideal $\left(A^{+}\right)$and negative ideal $\left(A^{-}\right)$solutions: While ideal solution consists of the best performance values of the weighted normal decision matrix, negative ideal solution consists of the worst performance values using Eq. (5) and Eq. (6).

$$
\begin{aligned}
& A^{+}=\left\{\max _{j} \mid j=1,2, \ldots, \mathrm{n} \text { ve } i=1,2, . ., m\right\} \\
& A^{-}=\left\{\min _{j} \mid j=1,2, \ldots, \mathrm{n} \text { ve } i=1,2, . ., m\right\}
\end{aligned}
$$

Step 5: Calculation of distance values with ideal solution and negative ideal solution: Distance from alternative $i$ to positive ideal solution $\left(S_{i}^{+}\right)$and to negative ideal solution $\left(S_{i}^{-}\right)$are calculated using Eq. (7) and Eq. (8), respectively.

$$
\begin{aligned}
& S_{i}^{+}=\sqrt{\sum_{j=1}^{n}\left(V_{i j}-V_{j}^{+}\right)^{2}} \\
& S_{i}^{-}=\sqrt{\sum_{j=1}^{n}\left(V_{i j}-V_{j}^{-}\right)^{2}}
\end{aligned}
$$

Step 6: Calculation of relative convergence: $S_{i}^{+}$and $S_{i}^{-}$are used to calculate the relative convergence ( $C_{i}^{*}$ ) of each decision point to ideal solution. Relative convergence to ideal solution is calculated using Eq (9) and this value is between 0 and 1 . Higher values indicate higher success.

$$
C_{i}^{*}=\frac{S_{i}^{-}}{S_{i}^{-}+S_{i}^{+}}
$$

\subsection{VIKOR Method}

VIKOR (Vise Kriterijumska Optimizacija I Kompromisno Resenje) is a method developed by Opricovic (1998) for multi-criteria optimization of complex systems. This method is known as a method to choose between alternatives in the case of contradictory criteria and to focus on sorting these alternatives. Closeness of the ideal solution is the key part of the VIKOR method. Ideal alternatives are comparisons according to closeness measure (Opricovic,1998). Also, this method uses different summation functions and different normalization methods than TOPSIS method. Steps of VIKOR method are listed: 
Step 1: Determination of the best $\left(f_{j}^{+}\right)$and worst $\left(f_{j}^{-}\right)$values for each criterion: Let various alternatives are shown as $a_{1}, a_{2}, \ldots, a_{n}$ . For the criterion $i$, the measurement of the alternative $a_{j}$ is expressed as $f_{i j}$. Eq. (10) and Eq. (11) are used if criterion is a benefit, and Eq. (12) and Eq. (13) are used if the criterion represents a cost.

$f_{j}^{+}=\max \left(\mathrm{a}_{j i}\right) \quad j=1,2, \ldots, m$

$f_{j}^{-}=\min \left(\mathrm{a}_{j i}\right) \quad j=1,2, \ldots, m$

$f_{j}^{+}=\min \left(\mathrm{a}_{j i}\right) \quad j=1,2, \ldots, m$

$f_{j}^{-}=\max \left(\mathrm{a}_{j i}\right) \quad j=1,2, \ldots, m$

Step 2: Creation of the normalization matrix

$r_{i j}=\frac{f_{j}^{+}-a_{i j}}{f_{j}^{+}-f_{j}^{-}}$

Step 3: Calculation of the weighted normalization decision matrix $\left(V_{i j}\right)$ : This matrix is obtained by multiplying normality decision matrix elements by respective weights to show criterion weights $\left(w_{j}\right)$.

$V_{i j}=r_{i j} \times w_{j}$

Step 4: Determination of $S_{i}$ and $R_{i}$ values: Maximum group benefit is obtained from $\min _{i} S_{i}$ and minimum personal regret is calculated with $\min _{i} R_{i} \cdot S_{i}$ indicates mean values for alternative $\mathrm{i}, R_{i}$ states the worst group scores for alternative $i$. $w_{j}$ value in the formulation can be determined according to expert opinions or can be obtained by any of several criteria-based decision-making methods which allow calculation of criteria weights. In this study weights were determined with the help of AHP method.

$$
\begin{aligned}
& S_{i}=\sum_{j=1}^{n} w_{j} \cdot \frac{f_{j}^{+}-a_{i j}}{f_{j}^{+}-f_{j}^{-}} \\
& R_{i}=\max \left[w_{j} \cdot \frac{f_{j}^{+}-a_{i j}}{f_{j}^{+}-f_{j}^{-}}\right]
\end{aligned}
$$

Step 5: Calculation of $Q_{i}$ values: For each alternative, the $Q_{i}$ values determined according to the evaluation criteria with Eq. (22) indicate the maximum group utility. Value $\beta$ in equation represents weight value for strategy of maximum group utility, while value 1- $\beta$ represents minimum regret of opposing decision makers. In $Q_{i}$ values, if $\beta$ value is chosen bigger than 0,5 , it specifies the majority choice; if $\beta$ value is equal to 0,5 this indicates compromise. Apart from these $\beta$ states negative attitude.

$$
\begin{aligned}
& S^{+}=\min _{i} S_{i} \\
& S^{-}=\max _{i} S_{i} \\
& R^{+}=\min _{i} R_{i} \\
& R^{-}=\max _{i} R_{i} \\
& Q_{i}=\beta \cdot \frac{\left(S_{i}-S_{i}^{+}\right)}{\left(S_{i}^{-}-S_{i}^{+}\right)}+(1-\beta) \cdot \frac{\left(\mathrm{R}_{i}-R_{i}^{+}\right)}{\left(\mathrm{R}_{i}^{-}-R_{i}^{+}\right)}
\end{aligned}
$$

Step 6: Ranking of alternatives for $S_{i}, R_{i}$ and $Q_{i}$ values: The rank of alternatives is determined by sorting obtained values from small to large.

Step 7: Determination of acceptable advantage $\left(C_{1}\right)$ and acceptable stability $\left(C_{2}\right)$ clusters: If the following two conditions are provided, $A_{1}$ is recommended as the compromised solution. For any alternative to take place in the $C_{1}$ cluster, it is necessary to provide the condition shown in (24). Value of the $D Q$ in equation is calculated by using Eq. (23). Where $\mathrm{m}$ is the number of alternatives.

$$
\begin{aligned}
& D Q=\frac{1}{1-m} \\
& Q\left(A_{2}\right)-Q\left(A_{1}\right) \geq D Q
\end{aligned}
$$


Set of acceptable stability ( $C_{2}$ ) consists of alternatives in taking place in the same order of $S_{i}$ or $R_{i}$ with $Q_{i}$ order. Alternatives in both $C_{1}$ and $C_{2}$ clusters indicate stable decision points.

\section{RANKING with AHP-TOPSIS and AHP-VIKOR}

\subsection{Identification Criteria and Calculate the Weights}

Criteria to be considered in the determination the most important inventory item are determined with expert. Literature studies (Ertugrul and Tanriverdi, 2013; Özdemir and Özveri, 2013; Partovi and Burton, 1993) and experiences of expert are benefited in this stage and 5 criteria to be used for the most inventory item determination are defined. Criteria and definitions of importance are shown in Table 5. It is possible to obtain quantitative information on price, demand and delivery time from 5 criteria, but criteria of criticality and substitution possibilities can be obtained qualitatively.

Table 5. Inventory evaluation criteria and its definition

\begin{tabular}{ll}
\hline Criterion & Definition of Importance \\
\hline Price & Expression as currency of each inventory items. \\
Demand & Amount of demand made in the inventory item within a year \\
Delivery Time & Time interval between when an inventory order is placed and when the product is delivered to the firm \\
Substitution & Whether or not there is another inventory that can be used in place of any inventory item \\
Criticality & How important is inventory to keep the production cycle running? \\
\hline
\end{tabular}

After determining criteria, 15 alternative products, which are wanted to be compared by expert, were identified. Decision hierarchy structured with selected alternative items and criteria is given in Figure 1. There are three levels in the decision hierarchy structured for this problem. Goal of decision process identified as Determination of the most important inventory item is in the first level of hierarchy. Criteria are in the second level and alternative inventory items are in the third and bottom level of hierarchy.

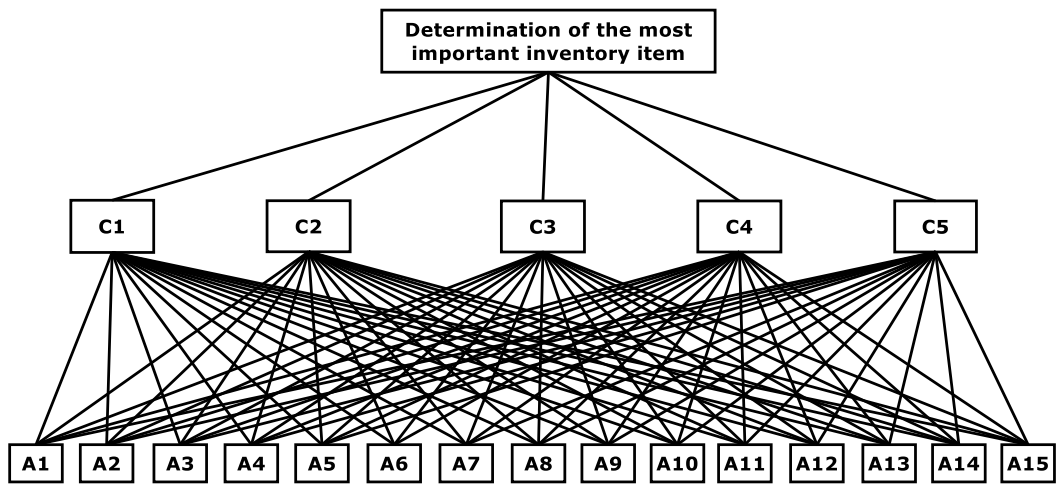

Figure 1. Hierarchy of multi criteria decision process

Table 6. Pairwise comparison matrix for criteria

\begin{tabular}{|c|c|c|c|c|c|}
\hline & C1 & $\mathrm{C} 2$ & C3 & $\mathrm{C} 4$ & C5 \\
\hline $\mathrm{C} 1$ & 1.00 & 0.50 & 3.00 & 5.00 & 7.00 \\
\hline $\mathrm{C} 2$ & 2.00 & 1.00 & 3.00 & 7.00 & 5.00 \\
\hline C3 & 0.33 & 0.33 & 1.00 & 3.00 & 3.00 \\
\hline $\mathrm{C} 4$ & 0.20 & 0.14 & 0.33 & 1.00 & 0.50 \\
\hline $\mathrm{C} 5$ & 0.14 & 0.20 & 0.33 & 2.00 & 1.00 \\
\hline
\end{tabular}

$\mathrm{C} 2$ is found as the most important criteria in the inventory item determination by AHP. Consistency index, Random index and consistency ratio of pairwise comparison matrix are calculated respectively as $0,039,1,12$ and 0,035 . Consistency ratio is smaller than 0,10 . Therefore weights of criteria are stated as consistent and they can be used in determination process. Because values are consistent, the relative importance values obtained can be used as weights.

Table 7. AHP Results

\begin{tabular}{lll}
\hline Criteria & Weight & $\begin{array}{l}\lambda_{\text {max }}, \mathrm{CI}, \mathrm{RI}, \\
\mathrm{CR}\end{array}$ \\
\hline $\mathrm{C} 1$ & 0,32 & $\lambda_{\max }=5,516$ \\
$\mathrm{C} 2$ & 0,42 & \\
$\mathrm{C} 3$ & 0,14 & $\mathrm{CI}=0,039$ \\
$\mathrm{C} 4$ & 0,05 & $\mathrm{RI}=1,12$ \\
$\mathrm{C} 5$ & 0,07 & $\mathrm{CR}=0,035$ \\
\hline & & 168
\end{tabular}




\subsection{Determine the ranking with AHP-TOPSIS}

Decision matrix in which alternatives are evaluated for each criterion, are formed in this stage. This matrix is converted to normalize decision matrix using Eq. (3) and is presented (Table 8). The weighted normalized decision matrix is constructed by multiplying the criteria weight calculated by AHP of elements in each column of the normalized decision matrix.

Table 8. Normalize unweighted and weighted decision matrix

\begin{tabular}{llllll|lllllll}
\hline \multicolumn{7}{l}{ Normalize unweighted decision matrix } & \multicolumn{7}{c}{ Normalize weighted decision matrix } \\
\hline Alternatives & C1 & C2 & C3 & C4 & C5 & Alternatives & C1 & C2 & C3 & C4 & C5 \\
\hline A1 & 0,026 & 0,05 & 0,089 & 0,032 & 0,104 & A1 & 0,008 & 0,021 & 0,012 & 0,002 & 0,007 \\
A2 & 0,025 & 0,048 & 0,086 & 0,032 & 0,1 & A2 & 0,008 & 0,020 & 0,012 & 0,002 & 0,007 \\
A3 & 0,032 & 0,042 & 0,095 & 0,032 & 0,084 & A3 & 0,010 & 0,018 & 0,013 & 0,002 & 0,006 \\
A4 & 0,028 & 0,11 & 0,068 & 0,026 & 0,094 & A4 & 0,009 & 0,046 & 0,010 & 0,001 & 0,007 \\
A5 & 0,03 & 0,095 & 0,056 & 0,022 & 0,075 & A5 & 0,010 & 0,040 & 0,008 & 0,001 & 0,005 \\
A6 & 0,038 & 0,064 & 0,053 & 0,019 & 0,06 & A6 & 0,012 & 0,027 & 0,007 & 0,001 & 0,004 \\
A7 & 0,037 & 0,078 & 0,044 & 0,016 & 0,047 & A7 & 0,012 & 0,033 & 0,006 & 0,001 & 0,003 \\
A8 & 0,028 & 0,034 & 0,041 & 0,013 & 0,055 & A8 & 0,009 & 0,014 & 0,006 & 0,001 & 0,004 \\
A9 & 0,03 & 0,034 & 0,038 & 0,011 & 0,045 & A9 & 0,010 & 0,014 & 0,005 & 0,001 & 0,003 \\
A10 & 0,012 & 0,2 & 0,162 & 0,08 & 0,076 & A10 & 0,004 & 0,084 & 0,023 & 0,004 & 0,005 \\
A11 & 0,012 & 0,15 & 0,145 & 0,076 & 0,053 & A11 & 0,004 & 0,063 & 0,020 & 0,004 & 0,004 \\
A12 & 0,018 & 0,027 & 0,079 & 0,07 & 0,057 & A12 & 0,006 & 0,011 & 0,011 & 0,004 & 0,004 \\
A13 & 0,207 & 0,024 & 0,018 & 0,229 & 0,071 & A13 & 0,066 & 0,010 & 0,003 & 0,011 & 0,005 \\
A14 & 0,207 & 0,019 & 0,01 & 0,173 & 0,053 & A14 & 0,066 & 0,008 & 0,001 & 0,009 & 0,004 \\
A15 & 0,207 & 0,026 & 0,011 & 0,154 & 0,057 & A15 & 0,066 & 0,011 & 0,002 & 0,008 & 0,004 \\
\hline
\end{tabular}

Determining positive ideal and negative ideal points of each criteria, distances of each alternative to positive ideal ( $S_{i}^{+}$) and negative ideal $\left(S_{i}^{-}\right)$points are calculated. At last stage relative closeness $\left(C_{i}\right)$ to positive ideal solution is calculated and alternatives are ranked according to these values (Table 9).

Table 9. TOPSIS results

\begin{tabular}{lrrr}
\hline Alternatives & \multicolumn{2}{c}{$S_{1}^{+}$} & \multicolumn{2}{l}{$S_{1}^{-}$} & \multicolumn{1}{l}{$C_{i}$} \\
\hline A1 & 0,087 & 0,018 & 0,172 \\
A2 & 0,088 & 0,017 & 0,164 \\
A3 & 0,088 & 0,017 & 0,161 \\
A4 & 0,071 & 0,040 & 0,359 \\
A5 & 0,074 & 0,033 & 0,309 \\
A6 & 0,081 & 0,022 & 0,210 \\
A7 & 0,077 & 0,026 & 0,255 \\
A8 & 0,093 & 0,009 & 0,091 \\
A9 & 0,092 & 0,009 & 0,092 \\
A10 & 0,063 & 0,079 & 0,557 \\
A11 & 0,066 & 0,058 & 0,467 \\
A12 & 0,096 & 0,011 & 0,102 \\
A13 & 0,077 & 0,063 & 0,453 \\
A14 & 0,079 & 0,063 & 0,443 \\
A15 & 0,076 & 0,063 & 0,452 \\
\hline
\end{tabular}

Based on $C_{i}$ values, ranking of alternatives in descending order is A10, A11, A13, A15, A14, A4, A5, A7, A6, A1, A2, A3, A12, A9, A8. TOPSIS results demonstrate that A10 is the most important alternative with $C_{i}$ value of 0,557 . When case in which criteria weights are not considered ranking of alternatives in descending order is A13, A14, A10, A15, A11, A4, A1, A3, A2, A5, A12, A7, A6, A8, A9. A13 is the most important alternative with $C_{i}$ value of 0,561.

This result indicates that the most important alternative has changed according to unweighted ranking results and criteria weights found significantly. So as to examplication relative closeness calculation, is calculated as follows (Eq. (25), Eq. (26), Eq. (27)) using Eq. (7), Eq. (8) and Eq. (9):

$S_{1}^{+}=\sqrt{(0,008-0,066)^{2}+(0,021-0,084)^{2}+(0,012-0,023)^{2}+(0,002-0,011)^{2}+(0,007-0,007)^{2}}=0,087$

$S_{1}^{-}=\sqrt{(0,008-0,004)^{2}+(0,021-0,008)^{2}+(0,012-0,001)^{2}+(0,002-0,001)^{2}+(0,007-0,003)^{2}}=0,018$ 
$C_{1}=\frac{S_{1}^{-}}{S_{1}^{-}+S_{1}^{+}}=\frac{0,018}{0,018+0,087}=0,172$

\subsection{Determine the ranking with AHP-VIKOR}

For each criterion, the best $\left(f_{j}^{*}\right)$ and worst $\left(f_{j}^{-}\right)$values are found with the aid of the decision matrix. Decision matrix is converted to a weighted normalized decision matrix using Eq. (14) and Eq. (15). For each decision point, $S_{i}$ is calculated using Eq. (16), $R_{i}$ values are calculated with Eq. (17), and $Q_{i}$ values are calculated using Eq. (22). $S_{i}, R_{i}$ and $Q_{i}$ are presented in order from small to large (Table 10). Here, the $\beta$ value is taken as 0,5 .

Table 10. VIKOR Results

\begin{tabular}{llllll}
\hline Rank & $\mathrm{Si}$ & Rank & $\mathrm{Ri}$ & Rank & Qi \\
\hline A10 & 0,369 & A7 & 0,283 & A10 & 0,135 \\
A11 & 0,527 & A5 & 0,290 & A4 & 0,279 \\
A4 & 0,604 & A4 & 0,294 & A11 & 0,296 \\
A13 & 0,630 & A6 & 0,316 & A5 & 0,332 \\
A15 & 0,631 & A10 & 0,320 & A7 & 0,377 \\
A14 & 0,658 & A11 & 0,320 & A6 & 0,504 \\
A5 & 0,669 & A1 & 0,348 & A1 & 0,592 \\
A1 & 0,717 & A2 & 0,353 & A2 & 0,623 \\
A2 & 0,731 & A3 & 0,367 & A3 & 0,687 \\
A7 & 0,740 & A8 & 0,385 & A15 & 0,708 \\
A3 & 0,744 & A9 & 0,385 & A13 & 0,724 \\
A6 & 0,747 & A12 & 0,401 & A14 & 0,794 \\
A8 & 0,849 & A15 & 0,404 & A8 & 0,862 \\
A12 & 0,857 & A13 & 0,408 & A9 & 0,873 \\
A9 & 0,860 & A14 & 0,420 & A12 & 0,930 \\
\hline
\end{tabular}

The following calculations show that $C_{1}$ (Acceptable advantage) condition is satisfied.

$Q\left(A_{2}\right)-Q\left(A_{1}\right) \geq D Q$

$\mathrm{D}(\mathrm{Q})=1 / 14=0,0714$

$0,279-0,135=0,144$

$0,144 \geq 0,0714$

$C_{2}$ condition is checked after $C_{1}$ condition. To ensure the second condition, in $Q_{i}$ ranking, alternative in ith ranking must take place in ith ranking at least one of $S_{i}$ or $R_{i}$. When $Q_{i}$ values varying according to different B values were examined, since $75 \%$ of the sequences had the A10 alternative in the first rank (Table 11), $\beta$ value was accepted as 0,5 , assuming compromise. Due to the first alternative in $S_{i}$ sequence was A10, the second condition also was provided.

Table 11. Rankings of $Q_{i}$ according to different $\beta$ values

\begin{tabular}{llllllllll}
\hline \multicolumn{2}{l}{ Rank $_{\beta=0}$} & \multicolumn{2}{l}{ Rank $_{\beta=0,25}$} & \multicolumn{2}{l}{ Rank $_{\beta=0,50}$} & \multicolumn{2}{l}{ Rank $_{\beta=0,75}$} & \multicolumn{2}{l}{ Rank $_{\beta=1}$} \\
\hline A7 & - & A4 & 0,178 & A10 & 0,135 & A10 & 0,067 & A10 & - \\
A5 & 0,054 & A7 & 0,189 & A4 & 0,279 & A11 & 0,309 & A11 & 0,322 \\
A4 & 0,078 & A5 & 0,193 & A11 & 0,296 & A4 & 0,379 & A4 & 0,480 \\
A6 & 0,237 & A10 & 0,202 & A5 & 0,332 & A5 & 0,471 & A13 & 0,532 \\
A10 & 0,270 & A11 & 0,283 & A7 & 0,377 & A7 & 0,566 & A15 & 0,535 \\
A11 & 0,270 & A6 & 0,371 & A6 & 0,504 & A15 & 0,621 & A14 & 0,588 \\
A1 & 0,475 & A1 & 0,533 & A1 & 0,592 & A13 & 0,628 & A5 & 0,610 \\
A2 & 0,508 & A2 & 0,566 & A2 & 0,623 & A6 & 0,637 & A1 & 0,709 \\
A3 & 0,610 & A3 & 0,649 & A3 & 0,687 & A1 & 0,651 & A2 & 0,737 \\
A8 & 0,746 & A15 & 0,795 & A15 & 0,708 & A2 & 0,680 & A7 & 0,755 \\
A9 & 0,746 & A8 & 0,804 & A13 & 0,724 & A14 & 0,691 & A3 & 0,764 \\
A12 & 0,864 & A9 & 0,809 & A14 & 0,794 & A3 & 0,726 & A6 & 0,771 \\
A15 & 0,881 & A13 & 0,819 & A8 & 0,862 & A8 & 0,920 & A8 & 0,978 \\
A13 & 0,915 & A14 & 0,897 & A9 & 0,873 & A9 & 0,936 & A12 & 0,995 \\
A14 & 1,000 & A12 & 0,897 & A12 & 0,930 & A12 & 0,962 & A9 & 1,000 \\
\hline
\end{tabular}

\section{CONCLUSION}

In today's competitive world, businesses have begun to pay more attention to inventory management to be able to compete better in the business world and survive in this environment. Inventory management has critical importance for firms in terms of reducing inventory holding cost, keeping inventory levels at the required level and allocating generally limited funding sources to appropriate areas to provide a competitive advantage. When literature was examined, generally they were suggested inventory should be scaled down by classifying or clustering methods instead of managing the whole during inventory management. Thus, this management 
style helps to reduce holding costs and increasing customer satisfaction. One of the most used methods in inventory management is the multi-criteria decision-making method.

In terms of inventory management, the most important advantages of the multi-criteria decision-making method compared to other methods are that criteria can be determined by taking opinions of experts in this field, multiple criteria can be taken into consideration and both qualitative and quantitative evaluations can be used in decision process. In order to determine the most important product in terms of inventory management, rather than making decisions according to only demand and price criteria, opinions of firm managers should be taken, and studies done in the literature should be analyzed. It may be more advantageous for firm to decide according to analysis made by considering criteria identified in this way.

In this study, multi-criteria decision-making methods were applied to determine the most important product in terms of inventory management for alternatives selected by experts from products produced by a company producing agricultural tools. In the process of determining criteria, it was benefited from expert opinions and studies in literature (Partovi and Burton, 1993; Ertugrul and Tanriverdi, 2013; Özdemir and Özveri, 2013). Criteria weights were determined by performing AHP analysis. Utilizing these weights, TOPSIS and VIKOR methods are applied and alternatives were listed. When comparing the results, it was seen that A10 was the most important alternative in both methods.

\section{REFERENCES}

Aydın Keskin, G. and Ozkan, C. (2013). Multiple criteria ABC analysis with FCM clustering. Journal of Industrial Engineering, 2013.

Aydın, Ö. (2009). Hospital Location for Ankara with Fuzzy AHP. Dokuz Eylul University Faculty of Economics and Administrative Sciences Journal, 24(2), 2009.

Bhattacharya, A., Sarkar, B. and Mukherjee, S. K. (2007). Distance-based consensus method for ABC analysis. International Journal of Production Research, 45(15), 3405-3420.

Boulos, M. N. K. (2003). Location-based health information services: a new paradigm in personalised information delivery. International journal of health geographics, 2(1), 2.

Cakir, O. and Canbolat, M. S. (2008). A web-based decision support system for multi-criteria inventory classification using fuzzy AHP methodology. Expert Systems with Applications, 35(3), 1367-1378.

Chen, Y., Li, K. W., Kilgour, D. M. and Hipel, K. W. (2008). A case-based distance model for multiple criteria ABC analysis. Computers \& Operations Research, 35(3), 776-796.

Ertugrul, I. and Tanriverdi, Y. (2013). ABC Method for Stock Controls and the Application of the AHP Analysis to Yarn Company. International Journal of Alanya Faculty of Business, 5(1), 2013.

Görgülü, I., Korkmaz, M. and Eren, T. (2013). Analytic network process and TOPSIS methods with selection of optimal investment strategy. Sigma, 31, 203-213.

Hatefi, S. M. and Torabi, S. A. (2015). A common weight linear optimization approach for multicriteria ABC inventory classification. Advances in Decision Sciences, 2015.

Hwang, C. L. and Yoon, K. (1981). Methods for multiple attribute decision making. In Multiple attribute decision making (pp. 58191). Springer, Berlin, Heidelberg.

Kılıç, A., Aygün, S., Aydın Keskin, G. and Baynal, K. A. (2014). Variant Perspective to Multi Criteria ABC Analysis Problem: Fuzzy Analytic Hierarchy Process-Technique for Order Preference by Similarity to Ideal Solution. Pamukkale University Journal of Engineering Sciences, 20(5), 179-188.

Kumar, G. A., Anzil, A., Ashik, K., James, A. T. and Ashok, J. K. (2017). Effective Inventory Management system through selective inventory control. Imperial Journal of Interdisciplinary Research, 3(6).

May, B. I., Atkinson, M. P. and Ferrer, G. (2017). Applying inventory classification to a large inventory management system. Journal of Operations and Supply Chain Management, 10(1), 68-86.

Opricovic, S. (1998). Multicriteria optimization of civil engineering systems. Faculty of Civil Engineering, Belgrade, 2(1), 5-21.

Opricovic, S. and Tzeng, G. H. (2004). Compromise solution by MCDM methods: A comparative analysis of VIKOR and TOPSIS. European journal of operational research, 156(2), 445-455. 
Özdemir, A., Özveri, O. (2013). Application of Analytic Hierarchy Process Analysis in Multi-Criteria Inventory Classification. Dokuz Eylul University Faculty of Economics and Administrative Sciences Journal, 19(2).

Partovi, F. Y. and Burton, J. (1993). Using the analytic hierarchy process for ABC analysis. International Journal of Operations \& Production Management, 13(9), 29-44.

Saaty, T. L. (1980). The analytic hierarchy process: planning, priority setting, resources allocation. New York: McGraw, 281.

Zhou, P. and Fan, L. (2007). A note on multi-criteria ABC inventory classification using weighted linear optimization. European journal of operational research, 182(3), 1488-1491. 